www.jmscr.igmpublication.org

Index Copernicus Value: 79.54

ISSN (e)-2347-176x ISSN (p) 2455-0450

crossrefDOI: https://dx.doi.org/10.18535/jmscr/v7i1.121

\title{
Status of Coronary Atherosclerosis in Population of Patna, Bihar: An Autopsy Based Study
}

\author{
Authors \\ Sanjeev Kumar ${ }^{1}$, Aman Kumar ${ }^{2 *}$, Nikhil Goel ${ }^{3}$, Saroj K. Ranjan ${ }^{4}, M_{\text {Mukh }}$ Prasad $^{5}$, \\ Pinki Kumari ${ }^{6}$ \\ ${ }^{1}$ Associate Professor, ${ }^{2}$ Additional Professor, ${ }^{3,4}$ Junior Resident (Academic), ${ }^{5}$ Senior Resident \\ Department of F.M.T., Indira Gandhi Institute of Medical Sciences, Patna, India \\ *Corresponding Author \\ Aman Kumar \\ Email: dramankumarfmt@yahoo.in
}

\begin{abstract}
Objectives: Ischemic heart disease resulting from atherosclerosis of coronary arteries is the most common fatal cardiac disease found in autopsies. With increase in incidence of coronary heart diseases it became challenging in India. The study was designed to assess the histomorphological atherosclerotic changes in coronary arteries at autopsy and to find out the age and sex related prevalence of atherosclerosis in population of Patna, Bihar a district in North India. This study will help in collecting baseline information of prevalence of such lesions which will help in framing health care programs to prevent the formation of these lesions.

Methods: In the present study, a total of 125 cases were autopsied to study and grade atherosclerotic lesions in the coronaries. Slides were prepared by sections of these specimens and stained with hematoxylin and eosin for microscopic examination.

Results: Among 125 studied specimens (98 males and 27 females) atherosclerotic lesions was found in $83.20 \%$ cases. It was observed in $83.67 \%$ of the male and $81.48 \%$ of female specimens. Significant atheroma was detected in $49.03 \%$ Cases. Commonest type of atherosclerosis seen was grade 3. The most frequently involved branch was left anterior descending artery. Relative frequency of lesions increased with age.

Conclusions: With high prevalence of cardiovascular disease, the study of subclinical atherosclerosis is the need of the day to estimate the disease burden in the hidden portion of iceberg which are symptom free. In this study atherosclerotic lesions was observed in very young population which may be an indication that there is need of implementation of anti atherogenic preventive measures in young individuals. It also highlights the importance of cardiovascular risk factors screening from early ages.

Keywords: Atherosclerosis, Coronary arteries, Autopsy, American Heart Association classification.
\end{abstract}

\section{Introduction}

Cardiovascular disease globally becomes a major health problem with atherosclerosis being the major cause ${ }^{1}$. Ischemic heart diseases (IHD) due to atherosclerosis are the most common causes of cardiac deaths worldwide ${ }^{2}$. The incidence of coronary artery diseases has increased among Indians during the past three to four decades. A 
wide proportion of Indians are having increasing prevalence of cardiovascular disease and associated risk factors ${ }^{3}$.

Atherosclerosis is primarily a disease of elastic vessels (aorta, carotid, iliac, coronary) but the vessels of some organs like a heart, brain and kidney are likely target of atherosclerosis due to their special predelictions ${ }^{4}$.

Recent advances in the field of modern medicine with effective secondary prevention have increase life expectancy and an improvement in the quality of life. Despite these achievements, the prevalence of coronary artery disease (CAD) still remains high. However, the exact data on the prevalence of coronary atherosclerosis or are extremely diverse ${ }^{5}$.

Considering the variations in lifestyle, dietary and racial patterns in our population it is required to study the morphology and evolution of coronary atherosclerosis in our specific population.

Autopsy is considered as important tool for various pathologies, which are difficult to assess in the living ${ }^{6}$. Autopsy studies have been proved to be an effective method for assessing atherosclerosis especially in developing countries like India as in the living population it is difficult, invasive as well as expensive ${ }^{11}$. With the limited amount of resources available in rural and semiurban population in India for studying atherosclerosis, autopsy plays a major role in documenting the prevalence of atherosclerosis in the population. It also provides gives a valuable measure of the prevalence, grading and distribution pattern of atherosclerotic lesion. Studying the incidence of sub-clinical atherosclerosis in a population helps in framing health care plans for prevention and for reversal of atherosclerosis ${ }^{10}$. Since atherosclerosis is a major killer disease, which gives a major financial burden on the nation's economy in health sector, even slight reduction in its incidence goes a long way in constructing the health of the future generation of the nation. Hence, this study was made to find out the prevalence of atherosclerosis in the population of Patna district.

\section{Materials and Methods}

The study was conducted on 125 hearts obtained from autopsies conducted during April, 2015 to July, 2016 in the Department of Forensic Medicine and Toxicology, IGIMS, Patna, Bihar. Cause of death and patient identification was noted in each case. Identity of each subject was established prior to post mortem examination. Past medical history and family history were taken from case sheets and family members.

The hearts were fixed in 10\% formalin. The heart was dissected along the flow of blood. Left anterior descending artery (LAD), left circumflex artery (LCA), and right coronary artery (RCA) were dissected longitudinally until they entered the musculature. The exposed coronary arteries were examined grossly for any thickening, yellow streaks, frank plaque, thrombus, narrowing, and atherosclerosis. Bits measuring 03 to $05 \mathrm{~mm}$ across were taken from LAD, LCA, and RCA for microscopic assessment of atherosclerosis.

After routine processing and paraffin embedding 4 micro meter sections were taken. Microscopic grading of atherosclerosis was done using American Heart Association (AHA) classification of atherosclerosis. AHA criteria for grading atherosclerotic lesions ${ }^{7,9}$

- Grade 1 - isolated intimal foamy cells(minimal change)

- Grade 2 - numerous intimal foamy cellsoften in layers (fatty streaks)

- Grade 3-pools of extra cellular lipid withouta well-defined core (intermediate lesion orpre-atheroma)

- Grade 4 - well defined lipid core with luminalsurface covered by normal intima (atheromaor fibro plaque)

- Grade 5 - lipid core with a fibrous cap with orwithout calcification (fibro- atheroma)

- Grade 6 - fibro-atheroma with cap defectsuch as haemorrhage and thrombosis

- Grade 7 - calcification prominent

- Grade 8 - fibrous tissue change prominent The results are analyzed statistically using chi-square test. 


\section{JMSCR Vol||07||Issue||01||Page 706-711||January}

\section{Results}

The present study was conducted on 125 hearts of which 98 were males and 27 were females. The subjects in study were divided into different age groups according to the age at the time of death and also depending upon sex (Table 1). Most of the deceased belonged to 30 years to 39 years of age group (26.4\%) among which 26 were males and 7 were females $(p>0.05)$. The mean weight of heart in study sample was $284 \pm 74$ grams for males and $260 \pm 70$ grams for females.

Table 2 showing the degree of atherosclerosis found in different age groups and in both sexes. The incidence of atheromatous plaques was $83.67 \%$ in males and $81.48 \%$ in females. Overall incidence of atherosclerosis was $83.2 \%$ in study population. Below 20 years only 4 cases of atheroma was found, however significant atheroma appeared third decade onwards and thereafter there is gradual increase in both its frequency and severity from second to seventh decade. Maximum incidence was in the seventh decade of life $(p>0.05)$. Commonest type of atherosclerosis was grade 3. Significant atheroma i.e., grade 4 to grade 7 are found in $49.03 \%$ of cases. The incidence of atherosclerotic plaques and number of arteries involved became higher as the age increases.

Of total 51 cases with significant atheromas, left anterior descending was most commonly affected in $43(39.81 \%)$ cases, right coronary artery was involved in 38 (35.18\%) and left circumflex artery was involved in $36(33.33 \%)$ cases. (Table 3) $(\mathrm{p}>0.05)$

Table 1: Dispersion of study population according to Age and Sex

\begin{tabular}{|l|c|c|c|}
\hline Age group & Males & Females & Total (\%) \\
\hline$<20$ yrs & 3 & 1 & $4(3.2)$ \\
\hline $20-29$ & 21 & 9 & $30(24.0)$ \\
\hline $30-39$ & 26 & 7 & $33(26.4)$ \\
\hline $40-49$ & 19 & 2 & $21(16.8)$ \\
\hline $50-59$ & 16 & 7 & $23(18.4)$ \\
\hline $60-69$ & 10 & 1 & $11(8.8)$ \\
\hline$>69$ yrs & 3 & 0 & $3(2.4)$ \\
\hline Total & $98(78.4)$ & $27(21.6)$ & 125 \\
\hline
\end{tabular}

Table 2: Degree of Atherosclerosis Correlated With Age and Sex (= Total)

\begin{tabular}{|c|c|c|c|c|c|c|c|c|c|c|c|c|c|c|c|c|c|c|c|c|c|c|c|c|c|c|c|}
\hline \multirow{2}{*}{$\begin{array}{l}\text { Age } \\
\text { group }\end{array}$} & \multicolumn{3}{|c|}{ Grade 1} & \multicolumn{3}{|c|}{ Grade } & \multicolumn{3}{|c|}{ Grade 3} & \multicolumn{3}{|c|}{ Grade 4} & \multicolumn{3}{|c|}{ Grade 5} & \multicolumn{3}{|c|}{ Grade 6} & \multicolumn{3}{|c|}{ Grade 7} & \multirow[t]{2}{*}{ A } & \multicolumn{3}{|c|}{ Total } & \multicolumn{2}{|c|}{$\begin{array}{c}\text { Significant } \\
\text { Atheroma }\end{array}$} \\
\hline & $\mathbf{M}$ & $\mathbf{F}$ & $=$ & $\mathbf{M}$ & $\mathbf{F}$ & $=$ & $\mathbf{M}$ & $\mathbf{F}$ & $=$ & $\mathbf{M}$ & F & $=$ & M & $\mathbf{F}$ & $=$ & $\mathbf{M}$ & $\mathbf{F}$ & $=$ & $\mathbf{M}$ & $\mathbf{F}$ & $=$ & & $\mathbf{M}$ & $\mathbf{F}$ & $=$ & $\mathbf{n}$ & $\%$ \\
\hline$<20$ & 1 & 1 & 2 & & & 0 & 1 & & 1 & & & 0 & & & 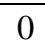 & & & 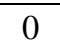 & & & 0 & 1 & 2 & 1 & 3 & 0 & 0.0 \\
\hline $20-29$ & 6 & 3 & 9 & & & 0 & 6 & 2 & 8 & 2 & 1 & 3 & & & 0 & & & 0 & & & 0 & 10 & 14 & 6 & 20 & 5 & 0 \\
\hline 30-39 & & & 0 & 1 & 2 & 3 & 8 & 2 & 10 & 6 & 1 & 7 & & & 0 & 3 & 1 & 4 & 2 & & 2 & 7 & 21 & 6 & 27 & 11 & 0.7 \\
\hline $40-49$ & & & & 3 & & 3 & 4 & 1 & 5 & 6 & & 6 & 2 & 1 & - & 1 & & 4 & 1 & & 1 & 2 & 17 & 2 & 19 & 12 & 63.15 \\
\hline $50-59$ & & & 0 & 2 & & 2 & 3 & 2 & 5 & 5 & 1 & 6 & 2 & 3 & 5 & 2 & 1 & 3 & 1 & & 1 & 1 & 15 & 7 & 22 & 13 & 59.09 \\
\hline $60-69$ & & & 0 & & & 0 & 2 & & 2 & 3 & 1 & 4 & & & 0 & 4 & & 4 & 1 & & 1 & 0 & 10 & 0 & 10 & 8 & 80.0 \\
\hline$>69$ & & & 0 & & & & 1 & & 1 & & & & & & 0 & 1 & & 1 & 1 & & 1 & 0 & 3 & 0 & 3 & 2 & 66.66 \\
\hline Total & 7 & 4 & 11 & 6 & 2 & 8 & 25 & 7 & 32 & 22 & 4 & 26 & 4 & 4 & 8 & 10 & 3 & 13 & 5 & 0 & 5 & 21 & 82 & 22 & 104 & 51 & 49.03 \\
\hline
\end{tabular}

Table 3: Dispersion of atherosclerosis in three major coronary arteries

\begin{tabular}{|l|c|c|c|c|c|c|}
\hline \multirow{2}{*}{ Grade } & \multicolumn{2}{|c|}{ RCA } & \multicolumn{2}{c|}{ LCA } & \multicolumn{2}{c|}{ LAD } \\
\cline { 2 - 7 } & $\mathbf{N}$ & \% & n & \% & n & \% \\
\hline 1 & 13 & 12.50 & 18 & 17.30 & 15 & 14.42 \\
\hline 2 & 12 & 11.53 & 16 & 15.38 & 14 & 13.46 \\
\hline 3 & 41 & 39.42 & 34 & 32.69 & 32 & 30.76 \\
\hline 4 & 19 & 18.26 & 25 & 24.03 & 27 & 25.96 \\
\hline 5 & 4 & 3.73 & 2 & 1.86 & 4 & 3.73 \\
\hline 6 & 9 & 8.41 & 8 & 7.47 & 8 & 7.47 \\
\hline 7 & 5 & 4.67 & 0 & 0.0 & 3 & 2.80 \\
\hline $4-7$ & 37 & 35.57 & 35 & 33.65 & 42 & 40.38 \\
\hline Total & 104 & & 104 & & 104 & \\
\hline
\end{tabular}


Table 4: Prevalence of CAD in Various studies

\begin{tabular}{|l|c|c|}
\hline Studies & Males (\%) & Females (\%) \\
\hline Present study & 78.4 & 21.6 \\
\hline Agravat et al & 73.7 & 26.3 \\
\hline Bhargava et al & 74.8 & 24.2 \\
\hline Murthy et al & 82 & 18 \\
\hline Padmavathi & 66.5 & 33.5 \\
\hline Singh et al & 85 & 15 \\
\hline Tandon & 66.5 & 33.5 \\
\hline
\end{tabular}

\section{Discussion}

There is considerable increase in the number of deaths due to coronary atherosclerosis in India and this number is probably expected to increase in the coming decades if not controlled. The most concern is the early age of CHD deaths in the developing countries as compared to the developed countries, which will definitely lame the major work force of our nation ${ }^{17,18}$.

As it increase with ageing, the basic need of the days are to assess the incidence of atherosclerosis in the young population. Prevalence of CAD in various studies were compared with present study table 4.In the present study 98 (78.4\%) cases were males and $27(21.6 \%)$ cases were females which are near similar to previous studies ${ }^{12,18 \text {, and } 19}$. As males are bread earners they are more exposed and vulnerable to accidents, violence and stress. Moreover males indulge more in smoking, alcoholism etc which definitely increases the risk of atherosclerosis.

The mean weight of heart in study sample was $284 \pm 74$ grams for males and $260 \pm 70$ grams for females which is comparable to the study of Monika Garg et $\mathrm{al}^{16}$ where in the weight was $289 \pm 71$ grams for males and $269 \pm 77$ grams for females.

American Heart Association characterized \& classified atherosclerotic lesions from type 1 to type 7. It was proposed that these lesions progressed from one type to the next. Recently plaque rupture is considered to be the most significant factor of thrombus mediated acute coronary syndrome. The pre-atheroma type was the most common type in our study (30.76\%), next in frequency was atheroma $(25.0 \%)$. In the studies of Sudha et $\mathrm{al}^{16}$, Virmani et $\mathrm{al}^{13}$ and Stary et $\mathrm{al}^{19}$ the most common type of lesion was ruptured plaque with the frequency of $11 \%, 37.5 \%$ and $33 \%$ respectively.

Atherosclerotic lesions develop quite early in life starting from age 20 years onwards. Overall incidence of atherosclerosis was found to be $49.03 \%$ which was comparable with the frequency given by Yazdi et al $(40 \%)^{2}$ and Golshahi et al $(28.9 \%){ }^{19}$.Significant atheroma appeared in third decade onwards $(25.0 \%)$ and there after its severity and frequency gradually increases from third decade onwards. Maximum incidence was in seventh decade $(80.0 \%)$.

In studies carried out by Yazdi et $\mathrm{al}^{2}$, Singh et $\mathrm{al}^{18}$ and Golshahi et $\mathrm{al}^{15}$ on different age groups, the prevalence of atherosclerosis was reported to be between $16 \%-75 \%$. The reason for this diversity could be the variability of culture (difference in dietary habits, different economic status), race, and various other environmental factors ${ }^{15}$.

In the present study the involvement of Left Anterior Descending artery, Right Coronary Artery and Left Circumflex Artery was 39.81\%, $35.18 \%$ and $33.33 \%$ respectively. The findings were similar to as observed by Sudha et al ${ }^{16}$, Monika et $\mathrm{al}^{14}$ and Yazdi et $\mathrm{al}^{2}$.

\section{Conclusion}

1) Incidence of atherosclerosis is more in males, but it is alarming in both sexes.

2) There is need of screening for cardiovascular risk factors from early ages of third decade to prevent some of the unexpected death.

3) The best possible way to study the prevalence of atherosclerosis in a population is autopsy based studies, as it is 
very difficult to study this in living persons.

4) it also help in estimating the future burden of atherosclerosis in our population, proper health policy framing and planning of preventive measures to be taken in order to serve the target population.

5) Similar studies should be carried out on regular time interval and with larger sample size to identify the risk factors.

\section{References}

1. Mohan V, Deepa R. Risk factors for coronary artery disease in Indians. J Assoc Physicians India. 2004; 52:95-7. [Pub Med]

2. Yazdi SA, Rezaei A, Azari JB, Hejazi A, Shakeri MT, Shahri MK. Prevalence of atherosclerotic plaques in autopsy cases with non cardiac death. Iran J Pathol. 2009; 4:101-4.

3. Indrayan A. Forecasting vascular disease cases and associated mortality in India. NCMH Background Papers: Burden of Disease in India. National Commission on Macroeconomics and Health, Government of India. 2005.

4. Schoen FJ. Blood vessels. In: Cotran RS, Kumar V, Robbins SL, eds. Pathological basis of disease. Philadelphia: W B Saunders, 1994:473-484.

5. Widimsky P, Andel M. Prevalence of coronary atherosclerosis in asymptomatic population. Eur Heart J 2000; 21: 13-14.

6. Fausto N. Atherosclerosis in young people: The value of the autopsy for studies of the epidemiology and pathobiology of disease. Am J Pathol. 1998; 153:1021-2. [PMC free article] [Pub Med]

7. Bertomeu A, Garcia- Vidal O, Farre X, Galobart A, Vazquez M, Laguna JC, Ros E. Preclinical coronary atherosclerosis in a population with low incidence of myocardial infarction: cross sectional study. BMJ 2003; 327:591-2.

8. Reddy SK, Yusuf S. Emerging epidemic of cardiovascular disease in developing countries. Circulation. 1998; 97:596-601. [Pub Med]

9. Stary HC. Natural History and Histological Classification of Atherosclerotic lesions: An Update. Arteriscler Thromb VascBiol 2000; 20:1177-1178.

10. Curtiss LK. Reversing Atherosclerosis? N Engl J Med. 2009; 360:1144-6. [Pub Med]

11. Naher S, Naushaba H, Muktadir G, Rahman MA, Khatun S, Begum M. Percentage area of intimal surface of the abdominal aorta affected by atherosclerosis: A Postmortem Study. J Med Sci Res. 2007; 9:26-30.

12. Bhargava MK, Bhargava SK. Coronary atherosclerosis in North Karnataka. Indian J PatholMicrobiol 1975; 18:65 77.

13. Virmani R, Kolodgie FD, Burke AP, Farb A, Schwartz SM. Lessons from sudden coronary death - Virmani R, Kolodgie FD, Burke AP, Farb A, Schwartz SM. Lessons from sudden coronary death - A comprehensive morphological classification scheme for atherosclerotic lesions. Arterioscler Thromb Vasc Biol 2000; 20:1262-75

14. Monika Garg, Akash Deep Agarwal, Sant Prakash Kataria. Coronary Atherosclerosis and Myocardial Infarction an Autopsy Study. J Indian Acad Forensic Med. JanMar 2011, Vol.33: 1; 39-42.

15. Golshahi J, Rojabi P, Golshahi F. Frequency of atherosclerotic lesions in coronary arteries of autopsy specimens in Isfahan forensic medicine center. J Res Med 2005; 1(10):16-9.

16. Sudha ML, Sundaram S, Purushothaman KR, Kumar PS, Prathiba D. Coronary atherosclerosis in sudden cardiac death: An autopsy study. Indian $\mathrm{J}$ Pathol Microbiol 2009;52(4):486-9 
17. Noeman A, Ahmad N, Azhar M. Coronary artery disease in young: Faulty life style or heredofamilial or both. Annals. 2007; 13:162-4.

18. Singh H, Oberoi SS, Gorea RK, Bal MS. Atherosclerosis in Coronaries in Malwa Region of Punjab. J Indian Acad Forensic Med 2005; 27(4):32-5.

19. Murthy MSN, Dutta BN, Ramalingaswami V. Coronary atherosclerosis in North India (Delhi Area). J Pathol Bacteriol 1963; 85:93-101 